\title{
Clinical Study \\ Pulmonary Effects of Neonatal Hydrocortisone Treatment in Ventilator-Dependent Preterm Infants
}

\author{
Sandra E. A. de Jong, Floris Groenendaal, Frank van Bel, and Karin J. Rademaker \\ Department of Neonatology, University Medical Center Utrecht/Wilhelmina Children's Hospital, P.O. Box 85090, \\ 3508 AB Utrecht, The Netherlands \\ Correspondence should be addressed to Karin J. Rademaker, k.rademaker@umcutrecht.nl
}

Received 24 June 2011; Accepted 21 September 2011

Academic Editor: Praveen Kumar

Copyright (๑) 2011 Sandra E. A. de Jong et al. This is an open access article distributed under the Creative Commons Attribution License, which permits unrestricted use, distribution, and reproduction in any medium, provided the original work is properly cited.

\begin{abstract}
Background/Objective. Hydrocortisone, administered to ventilated preterm neonates to facilitate extubation, has no adverse longterm effects, but short-term pulmonary effects have not been described previously. In the present study, we analyzed effects of hydrocortisone on ventilator settings and $\mathrm{FiO}_{2}$ in ventilator-dependent preterm infants. Patients and Methods. Fifty-five preterm children were included in this retrospective cohort study. Hydrocortisone was administered at a postnatal age of $>7$ days to treat chronic lung disease (CLD). Ventilator settings before and after hydrocortisone administration were recorded as well as $\mathrm{FiO}_{2}$ at 36 weeks' gestational age. Presence of cerebral palsy was assessed at a mean corrected age of 24.1 months. Results. Hydrocortisone administered at a median postnatal age of 14 days significantly reduced $\mathrm{FiO}_{2}$ from a median of 0.39 to 0.30 , mean airway pressure (MAP) from a median of $10.0 \mathrm{~cm} \mathrm{H}_{2} \mathrm{O}$ to $7.6 \mathrm{~cm} \mathrm{H}_{2} \mathrm{O}$, and $\mathrm{PaCO}_{2}$ from a median of $53.5 \mathrm{mmHg}$ to $47 \mathrm{mmHg}$. Extubation was achieved in all patients. CLD at 36 weeks was present in 11 of the 52 patients (21.1\%). None developed cerebral palsy. Conclusions. Hydrocortisone was effective in reducing the $\mathrm{FiO}_{2}, \mathrm{MAP}$, and $\mathrm{PaCO}_{2}$ and facilitated extubation. Hydrocortisone was not associated with cerebral palsy.
\end{abstract}

\section{Introduction}

Bronchopulmonary dysplasia (BPD) or chronic lung disease (CLD) was first described in 1967 as a severe form of lung disease in premature infants with severe respiratory distress syndrome, who received prolonged mechanical ventilation and high concentrations of oxygen [1]. Improved mechanically ventilatory strategies, and the introduction of antenatal glucocorticosteroids and postnatal surfactant treatment, have greatly reduced postnatal lung injury and increased survival of premature infants, resulting in a reported incidence of CLD of $8 \%-35 \%[2,3]$.

Still, CLD remains a significant problem in neonatal intensive care because of the significant cause of mortality, morbidity, and prolonged hospitalization [3]. Since inflammation plays an important role in the pathogenesis of CLD [3, 4], glucocorticosteroids, mainly dexamethasone, have been widely used to reduce CLD. Numerous studies show that dexamethasone improves short-term respiratory function, leading to a reduction in supplementary oxygen requirements and earlier extubation [5-7].

Despite its positive effect on neonatal lung function, dexamethasone therapy exerts several acute adverse effects, such as hyperglycemia, hypertension, and left ventricular hypertrophy. Concerns about the long-term benefits of this steroid in ventilator-dependent infants arose in the 1970s when it became clear that there was an increased risk of cerebral palsy after postnatal dexamethasone exposure [8]. In recent years, scientific evidence has accumulated on the longterm negative effects of neonatal dexamethasone treatment [9-11].

In contrast to other neonatal intensive care units (NICUs) in the Netherlands, the Wilhelmina Children's Hospital has historically always used the corticosteroid hydrocortisone instead of the more potent dexamethasone to treat ventilator-dependent preterm infants at risk for CLD 
because of fewer adverse effects and the apparently similar clinical benefits $[12,13]$. However, until now no studies have described the short-term effects of hydrocortisone treatment on respiratory function.

The purpose of this retrospective study is to analyze the immediate effect of hydrocortisone therapy on mechanical ventilation settings in ventilator-dependent preterm infants.

\section{Patients and Methods}

The study population presented in this retrospective cohort study consists of patients who were born after a gestational age of $\leq 32$ weeks and/or a birth weight of $\leq 1500$ grams between January 1, 2003 and December 31, 2007. These patients were consecutively admitted soon after birth over a period of five years to the Neonatal Intensive Care Unit of the Wilhelmina Children's Hospital, a tertiary referral centre.

One hundred and twenty-seven children born after a pregnancy of $\leq 32$ weeks and/or with a birth weight of $\leq 1500 \mathrm{~g}$ had been treated postnatally with corticosteroids for several reasons.

Nine patients received besides hydrocortisone also dexamethasone (two during part of their treatment in another hospital and seven prior to extubation) and were excluded to avoid contamination of hydrocortisone treatment effects.

One hundred and eighteen infants born after a pregnancy of $\leq 32$ weeks and/or with a birth weight of $\leq 1500$ g received hydrocortisone treatment. Two patients received hydrocortisone as a replacement therapy for their congenital adrenal hyperplasia. Fifty-three patients received hydrocortisone to treat hypotension.

Sixty-eight patients were treated with hydrocortisone to facilitate extubation. In one case, the attending neonatological staff decided to stop treatment after one day of hydrocortisone treatment because of severe respiratory insufficiency and the poor prognosis based on pulmonary hypoplasia as a result of PPROM.

In twelve children treated with nasal continuous positive airway pressure (nCPAP) after having been ventilated, hydrocortisone was administered in order to avoid re-intubation.

These thirteen children were excluded.

Four infants in whom hydrocortisone treatment was started while being ventilated died in neonatal period on day $13,18,22$, and 63; one of bullous emphysema and three of severe chronic lung injury with in one case in combination with a metabolic disorder of unspecified origin. These four children were not excluded.

Fifty-five out of the 118 children (46.6\%) received hydrocortisone treatment for prolonged ventilator dependency.

2.1. Eligibility Criteria. Infants were eligible for the study if they met the following criteria: (1) gestational age $\leq 32$ weeks and/or birth weight $\leq 1500 \mathrm{~g}$, (2) ventilator dependency based on signs of chronic lung disease, (3) hydrocortisone treatment, and (4) availability of data as defined in the study protocol. Infants who were treated with dexamethasone, for example, after referral from other NICUs, were excluded as well as infants who were not ventilator dependent but had CPAP for respiratory support.

\subsection{Study Protocol}

2.2.1. Demographic Variables. The following characteristics were retrospectively collected: gestational age (weeks), birth weight (grams), gender, small for gestational age $<\mathrm{p} 2.3$ (SGA), administration of antenatal steroids, premature prolonged rupture of membranes ( $>24$ hours, PPROM), Apgar scores, and surfactant therapy.

2.2.2. Ventilator Settings. The charts of all preterm infants born after a pregnancy of $\leq 32$ weeks and/or a birth weight $\leq 1500$ g receiving hydrocortisone treatment were systematically reviewed for ventilation dependency. It was clear that in several days before the start of hydrocortisone treatment, no positive changes were seen in ventilator settings.

Data on ventilator settings were recorded within an hour before the start of hydrocortisone therapy and again one day and two days later: inspiratory oxygen fraction $\left(\mathrm{FiO}_{2}\right)$, mean airway pressure (MAP; $\mathrm{cm} \mathrm{H}_{2} \mathrm{O}$ ), and arterial $\mathrm{PaCO}_{2}(\mathrm{~mm} \mathrm{Hg})$. Duration of mechanical ventilation and oxygen requirements at postmenstrual age of 36 weeks were documented.

2.2.3. Ventilation Policy. The targeted level of oxygen saturation and $\mathrm{PaCO}_{2}$ was $88-93 \%$ and $45-60 \mathrm{~mm} \mathrm{Hg}$, respectively.

2.2.4. Hydrocortisone Treatment. Generally, hydrocortisone was started when the postnatal age was at least more than 7 days and the child was ventilator-dependent with increasing oxygen requirements $\left(\mathrm{FiO}_{2}\right.$ more than 0.40$)$, prolonged dependency of extra oxygen $\left(\mathrm{FiO}_{2}\right.$ of more than 0.40$)$ based on chronic lung disease as evidenced by repeated pulmonary $\mathrm{X}$-rays. Echocardiography was performed in all patients to exclude a hemodynamically significant patent ductus arteriosus before considering hydrocortisone. Hydrocortisone was given at a starting dose of $5 \mathrm{mg} / \mathrm{kg} /$ day tapering off to $1.25 \mathrm{mg} / \mathrm{kg} /$ day over a 22 -day period. Depending on the response to therapy, steroid treatment was either prolonged or repeated. Weaning from the ventilator occurred on the basis of clinical condition and blood gases.

Postnatal age at start of treatment, number of days treated with hydrocortisone, and hydrocortisone dose $(\mathrm{mg} /$ $\mathrm{kg}$ mean weight; mean weight: weight at the end of the treatment plus weight at the start of treatment divided by two) over the treatment period were recorded.

2.2.5. Neurological Outcome. Infants were evaluated with a standardized neurologic examination at corrected ages of $0,6,15$, and 24 months using items from the methods of Amiel-Tison and Grenier [14], Touwen [15], and a Griffiths' assessment [16]. Each child was examined for the presence of cerebral palsy. If present, neuromotor abnormalities including tone abnormalities/presence and type of cerebral palsy were recorded. Cerebral palsy was defined as a nonprogressive central nervous system disorder characterized by abnormal muscle tone in at least one extremity and abnormal control of movement and posture $[8,17]$. 
TABLE 1: Patient characteristics.

\begin{tabular}{|c|c|c|}
\hline Characteristics & Total $(n=55)$ & $\%$ \\
\hline Gestational age $(w k)^{a}$ & $27.3 \pm 1.4$ & \\
\hline Birth weight $(\mathrm{g})^{\mathrm{a}}$ & $924 \pm 231$ & \\
\hline \multicolumn{3}{|l|}{ Gender $^{c}$} \\
\hline Female: male & $17: 38$ & \\
\hline SGA $(<\mathrm{p} 2.3)^{\mathrm{c}}$ & 4 & 7.3 \\
\hline Antenatal steroids ${ }^{c}$ & 47 & 85.5 \\
\hline $\mathrm{PROM}>24 \mathrm{~h}^{\mathrm{c}}$ & 12 & 21.8 \\
\hline \multicolumn{3}{|l|}{ Apgar score ${ }^{\mathrm{b}}$} \\
\hline At $1 \mathrm{~min}$ & $6(1-10)$ & \\
\hline At $5 \mathrm{~min}$ & $8(1-10)$ & \\
\hline Mortality ${ }^{c}$ & 4 & \\
\hline Postnatal age at death (days) & $13,18,22,63$ & \\
\hline Inotropes $^{c}$ & 38 & 69.1 \\
\hline Patent ductus arteriosus ${ }^{c}$ & 31 & 56.4 \\
\hline Indometacin & 30 & 96.8 \\
\hline Surgery & 12 \# & 38.7 \\
\hline $\mathrm{NEC}^{\mathrm{c}}$ & 2 & 3.6 \\
\hline NEC surgery requirement ${ }^{c}$ & 2 & 100 \\
\hline $\mathrm{IVH}^{\mathrm{c}}$ & 21 & 38.2 \\
\hline Grades I-II & 14 & - \\
\hline Grades III-IV & 7 & - \\
\hline Cystic PVL ${ }^{\mathrm{c}}$ (grade II) & 1 & - \\
\hline
\end{tabular}

Data are shown as ${ }^{\mathrm{a}}$ mean $\pm \mathrm{SD},{ }^{\mathrm{b}}$ median (range) or ${ }^{\mathrm{c}} n$.

SGA: small for gestational age, PROM: premature rupture of membranes, NEC: necrotizing enterocolitis, IVH: intraventricular haemorrhage, and PVL: periventricular leukomalacia.

\#In one case indometacin therapy was contraindicated because of IVH.

2.3. Study Endpoints. Primary outcome measures were ventilator settings after day 1 and day 2 of treatment, duration of mechanical ventilation, successful extubation after start of hydrocortisone, CLD at postmenstrual age of 36 weeks, mortality, and development of cerebral palsy.

2.4. Statistical Analysis. Data are summarized as means \pm SD or median and ranges. Data on respiratory function of day 0 , day 1 , and day 2, that is, $\mathrm{FiO} 2, \mathrm{MAP}$, and $\mathrm{PaCO}_{2}$ were pairwise compared using Wilcoxon rank sum. A $P$-value < 0.05 was considered statistically significant. All analyses were performed using SPSS version 15.0.1 for windows (SPSS, Chicago, Il, USA).

\section{Results}

Fifty-five ventilation-dependent children fulfilled the inclusion criteria and were included in the present retrospective study. Table 1 shows the most important patient characteristics whereas Table 2 shows respiratory characteristics.

Hydrocortisone was initiated at a median age of 11 days (Table 2 and Figure 1).

Median duration of hydrocortisone treatment was 21 days. In 52 out of 55 hydrocortisone-treated patients, the cumulative dose/kg mean weight could be calculated (mean

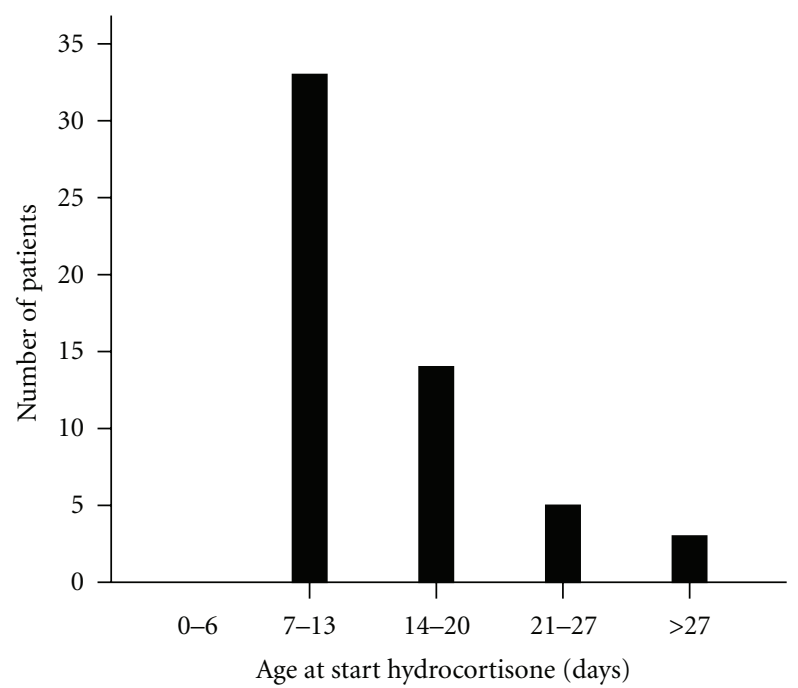

Figure 1: Age at start treatment with hydrocortisone.

TABLE 2: Respiratory characteristics.

\begin{tabular}{|c|c|c|}
\hline Characteristics & Total $(n=55)$ & $\%$ \\
\hline Duration of ventilation (days) ${ }^{b}$ & \multicolumn{2}{|c|}{$15.0(5-69) *$} \\
\hline HFOV before treatment ${ }^{c}$ & 34.0 & 61.8 \\
\hline Postnatal age at start of $\mathrm{HC}(\text { days })^{\mathrm{b}}$ & $11(7-44)$ & \\
\hline Duration of HC (days) ${ }^{\mathrm{d}}$ & $21.0(9.0)$ & \\
\hline HC dose (mg/kg mean weight $)^{\mathrm{d}}$ & $56.9(28.2)$ & \\
\hline Extubation after start HC (days) ${ }^{\mathrm{d}}$ & $4.0(4.0)$ & \\
\hline \multicolumn{3}{|l|}{$\operatorname{IRDS}^{\mathrm{c}}$} \\
\hline Grades I-II & 23 & 41.8 \\
\hline Grades III-IV & 32 & 58.2 \\
\hline \multicolumn{3}{|l|}{ Surfactant ${ }^{\mathrm{c}}$} \\
\hline No & 6 & 10.9 \\
\hline Yes & 49 & 89.1 \\
\hline Pneumothorax ${ }^{c}$ & 12 & 21.8 \\
\hline
\end{tabular}

Data are shown as ${ }^{b}$ median (range), ${ }^{c} n$ or ${ }^{d}$ median (interquartile range). HFOV: high frequency oscillation ventilation; HC: hydrocortisone; IRDS: infant respiratory distress syndrome.

* In one case it took 69 days to wean the child from ventilator because of ongoing sepsis.

weight: weight at the end of treatment plus weight at the start of treatment divided by two). Median cumulative hydrocortisone dose was $56.9 \mathrm{mg} / \mathrm{kg}$ mean weight.

3.1. Respiratory Effects. All 55 patients, who received hydrocortisone while being ventilated, could be successfully extubated at a median age of 4 days. In one case, it was hard to wean the child from the ventilator because of intercurrent periods of Staphylococcus epidermidis sepsis. This child was eventually weaned after 69 days.

Treatment with hydrocortisone was potent in reducing the need for extra oxygen (Figure 2). There was a significantly reduced requirement for oxygen after day $2(P$-value $=0.001)$ following start of hydrocortisone treatment and between day 1 and day 2 after start of hydrocortisone $(P$-value $=0.001)$. 


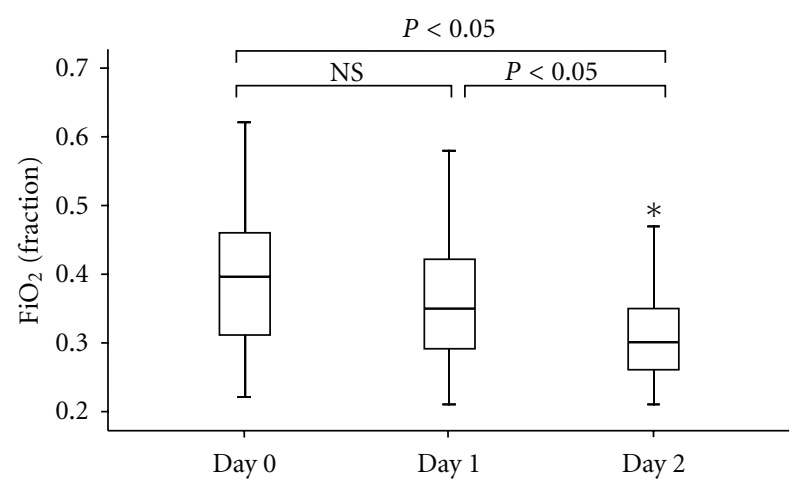

FIGURE 2: Values of oxygen requirement (inspirational oxygen fraction $\left.\left(\mathrm{FiO}_{2}\right)\right)$ on day 0 (baseline), day 1 , and day 2 following treatment with hydrocortisone (HC). ${ }^{*} P<0.05$ versus day 0 (baseline) and day 1 . NS $=$ non significant. $\mathrm{FiO}_{2}$ significantly decreases after day 2 compared with day 0 (baseline) and between day 1 and day 2 .

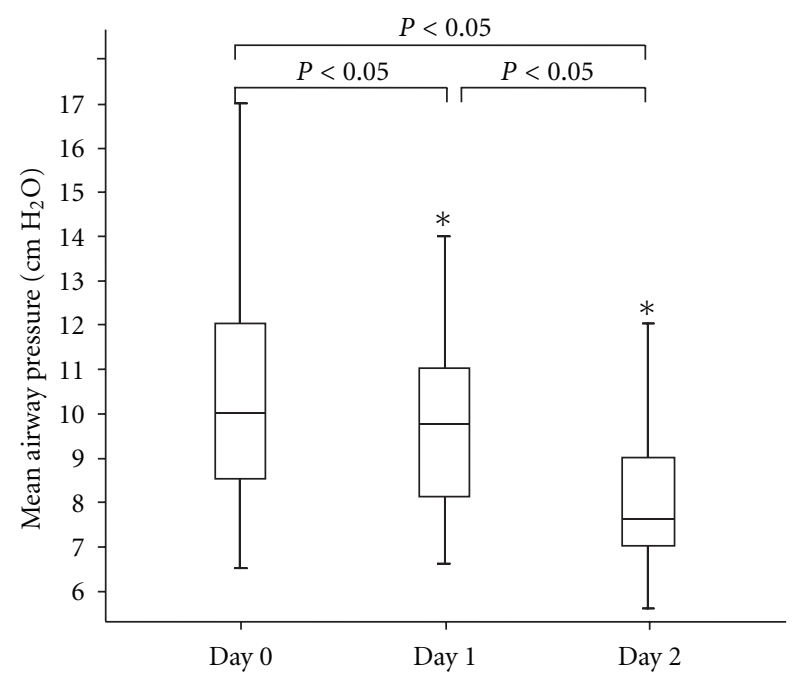

Figure 3: Values of Mean Airway Pressure $\left(\mathrm{cm} \mathrm{H}_{2} \mathrm{O}\right)$ on day 0 (baseline), day 1, and day 2 following treatment with hydrocortisone $(\mathrm{HC}) .{ }^{*} P<0.05$ versus day 0 (baseline) and day 1 . Mean airway pressure significantly decreases on day 1 and day 2 compared with day 0 (baseline).

No significant reduced oxygen requirement was seen after one day $(P$-value $=0.006)$.

Maximal effect of hydrocortisone treatment on MAP was seen after day 1 after start treatment (Figure 3 ). This effect was significant with a $P$-value of 0.002 . Furthermore, a significant effect was also seen after day 2 after start treatment $(P$-value $<0.001)$ and between day 1 and day $2(P$-value $<$ $0.001)$.

Hydrocortisone treatment had a maximal effect on $\mathrm{PaCO}_{2}$ one day after start treatment $(P$-value $<0.001)$ (Figure 4). No significant effect on $\mathrm{PaCO}_{2}$ was seen between day 1 and 2 after start hydrocortisone $(P$-value $=0.453)$.

After a gestational age of 36 weeks, 11 children (21.1\%) required supplemental oxygen. Four children died before

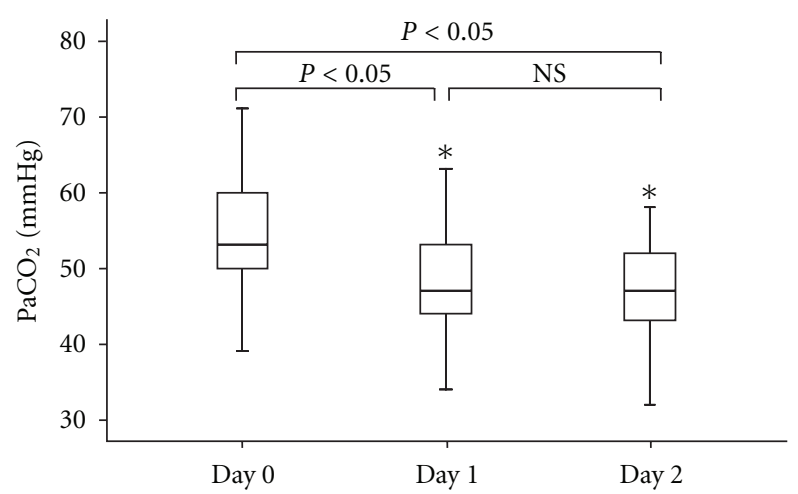

Figure 4: Values of $\mathrm{PaCO}_{2}(\mathrm{mmHg})$ on day 0 (baseline), day 1, and day 2 following treatment with hydrocortisone $(\mathrm{HC}) .{ }^{*} P<0.05$ versus day 0 (baseline) and day $1 . \mathrm{NS}=$ non significant. $\mathrm{PaCO}_{2}$ significantly decreases on day 1 and day 2 compared with day 0 (baseline).

gestational age of 36 weeks, and in one surviving case supplemental oxygen requirement was not noted.

3.2. Neurodevelopmental Followup. Fifty-five ventilationdependent children were included in this retrospective study. Of these, four were known to have died during neonatal period, leaving fifty-one patients available for followup at 24 months of corrected age (mean $24.1 \pm 0.27$ months). Standardized neurologic examination revealed that none of the 51 patients developed cerebral palsy.

\section{Discussion}

Our findings suggest that moderately early hydrocortisone therapy, in the dose mentioned, leads to a significant reduction in oxygen requirement $\left(\mathrm{FiO}_{2}\right), \mathrm{PaCO}_{2}$, and mean airway pressure in ventilator-dependent preterm infants more than 7 days old who were at risk for CLD.

Several studies indicate that low-dose dexamethasone administration after the first week of life significantly reduces the short-term pulmonary effects as failure to extubation and days of mechanical ventilation in ventilator-dependent preterm infants $[5,7,18]$.

The study of Doyle et al. reported that dexamethasone $(0.89 \mathrm{mg} / \mathrm{kg} / 10$ days $)$ given at a median treatment age of 23 days to ventilator-dependent extremely low birthweight infants improved ventilator and oxygen requirements substantially and shortened the duration of intubation. There was little evidence for a reduction in either the mortality rate or the rate of oxygen dependency at 36 weeks [5].

Another study found that moderately early low-dose dexamethasone therapy for 7 days (tapering course, 0.2 to $0.1 \mathrm{mg} / \mathrm{kg}$ ) had comparable beneficial effects to a high dose regimen. In both groups of infants (gestational age 2430 weeks; birth weight $550-1290 \mathrm{~g}$ ), $\mathrm{FiO}_{2}$ and MAP were significantly reduced [18].

A recent systematic review of 16 randomized, placebocontrolled trials (RTCs) including 1136 randomly assigned ventilated preterm infants more than 7 days of age assessed the effects of different cumulative dexamethasone doses on 
CLD and neurodevelopmental outcome. This paper con cluded that higher cumulative dexamethasone doses $(\geq 4 \mathrm{mg}$ / $\mathrm{kg}$ ) administered after the first week of life may decrease the relative risk for the combined outcome CLD or mortality. The risk of mortality or cerebral palsy was decreased by $6.2 \%$ for each incremental $\mathrm{mg} / \mathrm{kg}$ cumulative dexamethasone dose when administered between 7-14 days of live. Furthermore, a significant reduction in short-term pulmonary effects as failure to extubation on day 3 and 7 and days of mechanical ventilation was seen in patients treated with dexamethasone after 7 days of live. These outcomes were independent of the cumulative dexamethasone dose [19].

Over the past years, concerns on the long-term neurodevelopmental consequences after dexamethasone therapy arose, when followup of a randomized controlled trial revealed a marked increase in neurodevelopmental dysfunction in neonates treated with dexamethasone compared with controls [11]. Since then, more reports of long-term negative neurodevelopmental sequelae have been published [10, 20, 21], and as a result The American Academy of Pediatrics stated in 2002 [22] that postnatal steroid administration, outside clinical trials, should be limited to "exceptional clinical circumstances". In addition, a revised statement was issued by The American Academy of Pediatrics stating that current evidence is insufficient to make a recommendation regarding treatment with other glucocorticosteroids [23].

The long-term negative effects of dexamethasone necessitate a search for alternatives in the treatment of neonates with chronic lung disease. One of the possibilities frequently suggested in recent literature is the glucocorticosteroid hydrocortisone.

Few studies $[12,24-26]$ have investigated the use of hydrocortisone for treatment of CLD in premature infants and described long-term neurological outcomes, reviewed by Rademaker et al. [13].

Van der Heide-Jalving et al. retrospectively studied in a group of 25 preterm infants (mean gestational age 28.3 weeks; mean birth weight $1040 \mathrm{~g}$ ) the effect of highdose hydrocortisone on neurodevelopmental outcome. No significant differences were detected between the matched control group and hydrocortisone group with respect to neurological outcome, psychomotor development, and school performance at age 5-7 years. However, children treated with dexamethasone had a significantly less favourable school performance than their controls [12].

Another retrospective matched cohort study, Karemaker et al., compared behavioural outcome and motor skills in 192 preterm infants who neonatally either received dexamethasone or hydrocortisone for chronic lung disease. Dexamethasone- and hydrocortisone-treated groups were compared with a reference group and a group treated only antenatally with betamethasone. The groups were matched for gestational age, birth weight, gender, rate of respiratory distress syndrome, and rate of peri/intraventricular haemorrhage. At school age (7-10 years), the children treated with dexamethasone had a worse neurodevelopmental outcome than the reference group and betamethasone group, whereas the outcome of hydrocortisone-treated children did not differ from these two groups [24].
A large cohort study on long-term neurodevelopmental outcome in children following neonatal hydrocortisone treatment was reported in 2007 [25]. In this study, 226 preterm children ( 62 had been treated postnatally with hydrocortisone for CLD and 164 had not been treated with steroids) were followed up for 8 years. As this study was nonrandomized and treated children were generally sicker than untreated children, adjustments were made for gestational age, birth weight, gender, need for mechanical ventilation and small-for-gestational age. No differences were found in neurocognitive and motor performance between the two groups. Incidence of cerebral palsy and brain lesions on MRI was also similar.

Watterberg et al. reported that early low-dose hydrocortisone therapy for prophylaxis of early adrenal insufficiency to prevent bronchopulmonary dysplasia did not increase the incidence of cerebral palsy in extremely low birth weight infants. Treated infants had indicators of improved developmental outcome at 18 to 22 months' corrected age [26].

Recently, a prospective study was performed to evaluate the brain growth at term in preterm infants who did receive neonatal hydrocortisone for CLD. Thirty-eight preterm infants ( $n=19$ hydrocortisone, $n=19$ controls) were matched for gestational age at birth. There were no differences in cerebral tissue volumes between the two groups at term equivalent age. In conclusion, no effect on brain growth was shown after treatment with hydrocortisone for CLD [27].

Our study supports the suggestion that hydrocortisone is not associated with cerebral palsy at 24 months adjusted age. According to findings of a recent study, we would have expected to find 2-5 cases of CP in our patients [28].

In 2010, Doyle et al. reviewed systematically the data from eight randomised controlled trials in newborn infants where hydrocortisone was compared with placebo to establish the balance between risks and benefits of hydrocortisone in newborn infants in the prevention or treatment of CLD [29]. In all eight trials, treatment was started in the first week of life; there were no trials of treatment started in infants who were chronically ventilated-dependent after the first week of life. A meta-analysis demonstrated little evidence to support the use of hydrocortisone (ranging in dose from 5 to $15 \mathrm{mg} / \mathrm{kg}$ ) to prevent CLD; there were no improvements in important outcomes of mortality, or of rates in CLD or home oxygen dependence.

To our knowledge, no studies are performed that assess the short-term pulmonary effects following hydrocortisone treatment. Our study provides the first evidence that, besides dexamethasone, hydrocortisone also facilitates extubation, reduces oxygen and ventilator requirements. Since shortterm pulmonary effects of dexamethasone and hydrocortisone are clinical comparable, and dexamethasone has proven long-term negative adverse effects, studies to use hydrocortisone in preterm ventilator-dependent infants at risk for CLD are warranted. 
4.1. Limitations of the Study. The present study has also limitations. The primary limitation of our study is the lack of a control group. This lack is mainly related to its retrospective nature.

Furthermore, the data obtained in this study were limited by the fact that we performed a retrospective cohort study and not a randomized prospective study.

The sample size of our study population is small. The fifty-five patients in this study were born with a gestational age $\leq 32$ weeks and/or birthweight of $\leq 1500$ grams admitted over a period of five years to our NICU. Only a relatively small group fulfilled our inclusion criteria, a large group received hydrocortisone for other reasons than weaning from the ventilator.

Bearing in mind the above considerations, the results of this study still provides useful information.

We are convinced that this is the first step towards considering hydrocortisone as a therapy for prolonged ventilatordependent children at risk for CLD. Finally, the results of the present study urge for a large double-blind randomized controlled trial on hydrocortisone versus placebo treatment for ventilator-dependent children at risk for CLD to clarify the discussion about which corticosteroid (dexamethasone or hydrocortisone) is safer for treatment of preterm infants with chronic lung injury.

\section{References}

[1] W. H. Northway, R. C. Rosan, and D. Y. Porter, "Pulmonary disease following respirator therapy of hyaline-membrane disease. Bronchopulmonary dysplasia," New England Journal of Medicine, vol. 276, no. 7, pp. 357-368, 1967.

[2] J. Hentschel, T. M. Berger, A. Tschopp, M. Müller, M. Adams, and H. U. Bucher, "Population-based study of bronchopulmonary dysplasia in very low birth weight infants in Switzerland," European Journal of Pediatrics, vol. 164, no. 5, pp. 292-297, 2005.

[3] J. A. Lemons, C. R. Bauer, W. Oh et al., "Very low birth weight outcomes of the National Institute of Child health and human development neonatal research network, January 1995 through December 1996. NICHD Neonatal Research Network," Pediatrics, vol. 107, no. 1, p. E1, 2001.

[4] C. P. Speer, "Pulmonary inflammation and bronchopulmonary dysplasia," Journal of Perinatology, vol. 26, supplement 1, pp. S57-S62, 2006.

[5] L. W. Doyle, P. G. Davis, C. J. Morley et al., "Low-dose dexamethasone facilitates extubation among chronically ventilatordependent infants: a multicenter, international, randomized, controlled trial," Pediatrics, vol. 117, no. 1, pp. 75-83, 2006.

[6] D. G. Grier and H. L. Halliday, "Corticosteroids in the prevention and management of bronchopulmonary dysplasia," Seminars in Neonatology, vol. 8, no. 1, pp. 83-91, 2003.

[7] G. Suske, K. Oestreich, V. Varnholt, P. Lasch, and W. Kachel, "Influence of early postnatal dexamethasone therapy on ventilator dependency in surfactant-substituted preterm infants," Acta Paediatrica, vol. 85, no. 6, pp. 713-718, 1996.

[8] B. Hagberg, G. Hagberg, and I. Olow, "The changing panorama of cerebral palsy in Sweden 1954-1970. II. Analysis of the various syndromes," Acta Paediatrica Scandinavica, vol. 64, no. 2, pp. 193-200, 1975.
[9] E. C. Eichenwald and A. R. Stark, "Are postnatal steroids ever justified to treat severe bronchopulmonary dysplasia?" Archives of Disease in Childhood, vol. 92, no. 5, pp. F334-F337, 2007.

[10] E. S. Shinwell, M. Karplus, D. Reich et al., "Early postnatal dexamethasone treatment and increased incidence of cerebral palsy," Archives of Disease in Childhood, vol. 83, no. 3, pp. F177-F181, 2000.

[11] T. F. Yeh, Y. J. Lin, C. C. Huang et al., "Early dexamethasone therapy in preterm infants: a follow-up study," Pediatrics, vol. 101, no. 5, p. E7, 1998.

[12] M. Van Der Heide-Jalving, P. J. G. H. Kamphuis, M. J. Van Der Laan et al., "Short- and long-term effects of neonatal glucocorticoid therapy: is hydrocortisone an alternative to dexamethasone?" Acta Paediatrica, vol. 92, no. 7, pp. 827-835, 2003.

[13] K. J. Rademaker, L. S. De Vries, C. S. P. M. Uiterwaal, F. Groenendaal, D. E. Grobbee, and F. Van Bel, "Postnatal hydrocortisone treatment for chronic lung disease in the preterm newborn and long-term neurodevelopmental followup," Archives of Disease in Childhood, vol. 93, no. 1, pp. F58F63, 2008.

[14] C. Amiel-Tison and A. Grenier, Evaluation Neurologique du Nouveau-ne et du Nourrisson, Masson, Paris, France, 1980.

[15] B. C. L. Touwen, Examination of the Child with Minor Neurological Dysfunction, no. 71, Clinics in Developmental Medicine, SIMP/Heinemann, London, UK, 1979.

[16] R. Griffiths, The Abilities of Babies: A Study in Mental Meas urement, Association of Research in Infant and Child Development, Amersham, Bucks, UK, 1976.

[17] L. Mutch, E. Alberman, B. Hagberg, K. Kodama, and M. V. Perat, "Cerebral palsy epidemiology: where are we now and where are we going?" Developmental Medicine and Child Neurology, vol. 34, no. 6, pp. 547-551, 1992.

[18] M. Durand, M. E. Mendoza, P. Tantivit, A. Kugelman, and C. McEvoy, "A randomized trial of moderately early lowdose dexamethasone therapy in very low birth weight infants: dynamic pulmonary mechanics, oxygenation, and ventilation," Pediatrics, vol. 109, no. 2 I, pp. 262-268, 2002.

[19] W. Onland, M. Offringa, A. P. D. Jaegere, and A. H. Van Kaam, "Finding the optimal postnatal dexamethasone regimen for preterm infants at risk of bronchopulmonary dysplasia: a systematic review of placebo-controlled trials," Pediatrics, vol. 123, no. 1, pp. 367-377, 2009.

[20] T. M. O'Shea, J. M. Kothadia, K. L. Klinepeter et al., "Randomized placebo-controlled trial of a 42-day tapering course of dexamethasone to reduce the duration of ventilator dependency in very low birth weight infants: outcome of study participants at 1-year adjusted age," Pediatrics, vol. 104, no. 1 I, pp. 15-21, 1999.

[21] T. F. Yeh, Y. J. Lin, H. C. Lin et al., "Outcomes at school age after postnatal dexamethasone therapy for lung disease of prematurity," New England Journal of Medicine, vol. 350, no. 13, pp. 1304-1313, 2004.

[22] L. R. Blackmon, E. F. Bell, W. A. Engle et al., "Postnatal corticosteroids to treat or prevent chronic lung disease in preterm infants," Pediatrics, vol. 109, no. 2, pp. 330-338, 2002.

[23] K. L. Watterberg, L.-A. Papile, D. H. Adamkin et al., "Postnatal corticosteroids to prevent or treat bronchopulmonary dysplasia," Pediatrics, vol. 126, no. 4, pp. 800-808, 2010.

[24] R. Karemaker, C. J. Heijnen, S. Veen et al., "Differences in behavioral outcome and motor development at school age after 
neonatal treatment for chronic lung disease with dexamethasone versus hydrocortisone," Pediatric Research, vol. 60, no. 6, pp. 745-750, 2006.

[25] K. J. Rademaker, C. S. P. M. Uiterwaal, F. Groenendaal et al., "Neonatal hydrocortisone treatment: neurodevelopmental outcome and MRI at school age in preterm-born children," Journal of Pediatrics, vol. 150, no. 4, pp. 351-357, 2007.

[26] K. L. Watterberg, M. L. Shaffer, M. J. Mishefske et al., "Growth and neurodevelopmental outcomes after early lowdose hydrocortisone treatment in extremely low birth weight infants," Pediatrics, vol. 120, no. 1, pp. 40-48, 2007.

[27] M. J. N. L. Benders, F. Groenendaal, F. Van Bel et al., "Brain development of the preterm neonate after neonatal hydrocortisone treatment for chronic lung disease," Pediatric Research, vol. 66, no. 5, pp. 555-559, 2009.

[28] F. Groenendaal, J. Termote, M. Van Der Heide-Jalving, I. Van Haastert, and L. De Vries, "Complications affecting preterm neonates from 1991 to 2006: what have we gained?" Acta Paediatrica, vol. 99, no. 3, pp. 354-358, 2010.

[29] L. W. Doyle, R. A. Ehrenkranz, and H. L. Halliday, "Postnatal hydrocortisone for preventing or treating bronchopulmonary dysplasia in preterm infants: a systematic review," Neonatology, vol. 98, no. 2, pp. 111-117, 2010. 


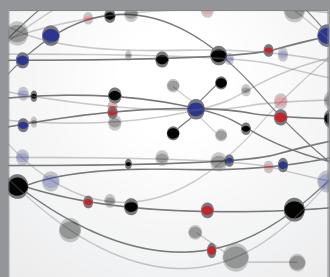

The Scientific World Journal
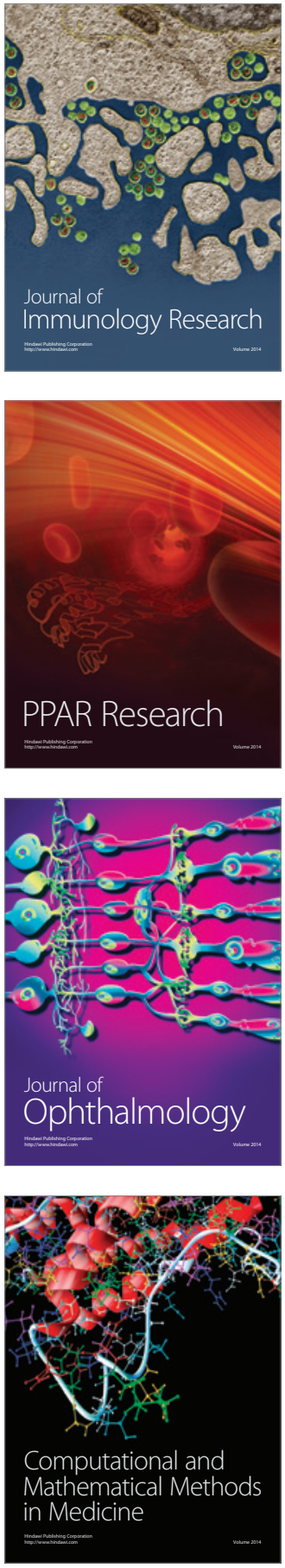

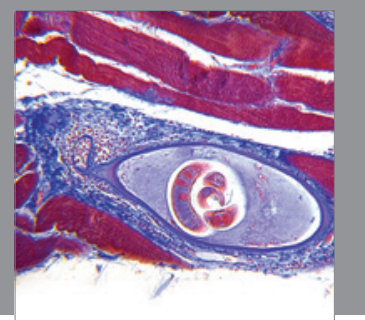

Gastroenterology

Research and Practice
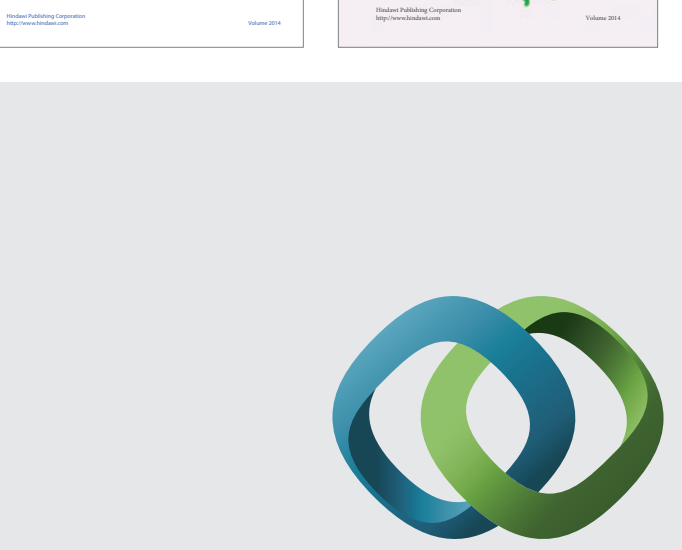

\section{Hindawi}

Submit your manuscripts at

http://www.hindawi.com
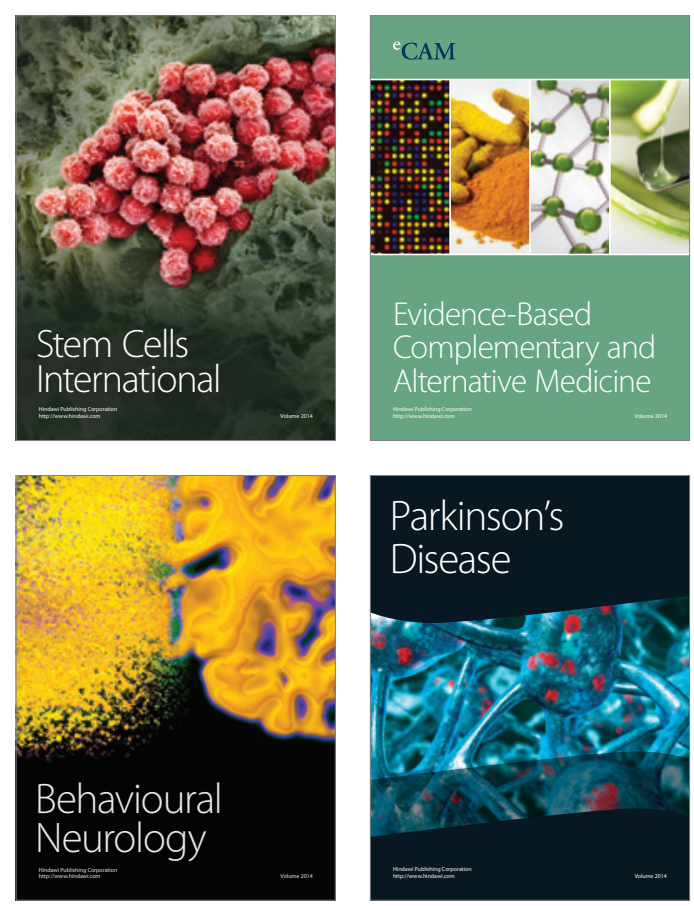

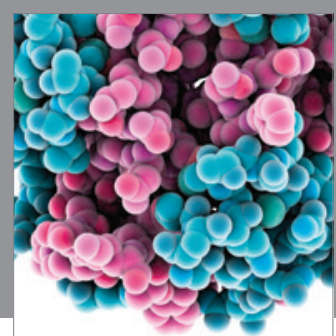

Journal of
Diabetes Research

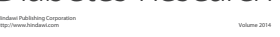

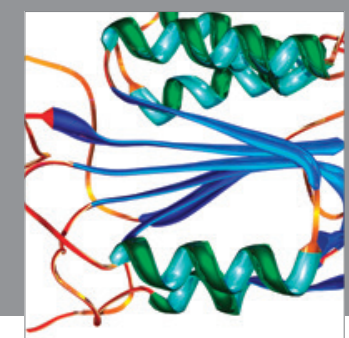

Disease Markers
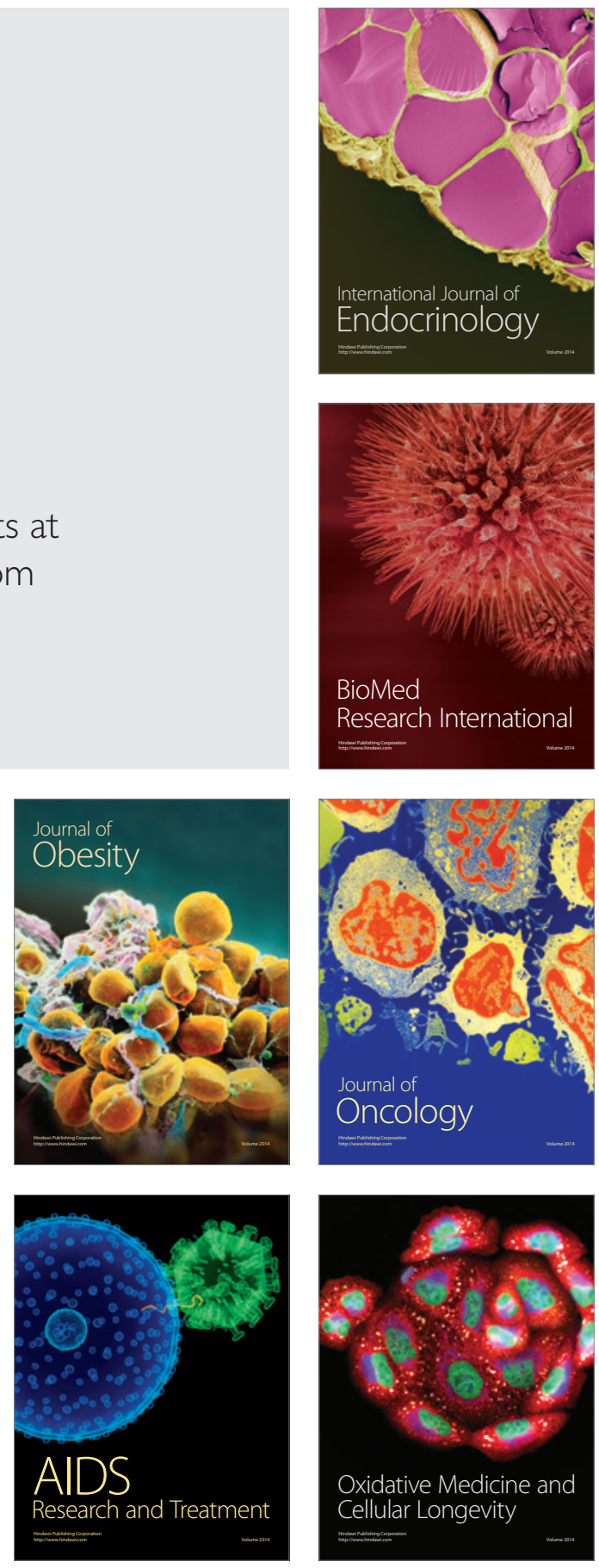